OPEN ACCESS

Edited by:

Huang Wei,

Second Institute of Oceanography, Ministry of Natural Resources, China

Reviewed by:

Jaclyn Hill,

Maurice Lamontagne Institute,

Fisheries and Oceans Canada,

Canada

Gilles Lepoint

Fonds National de la Recherche Scientifique (FNRS), Belgium Chang-Keun Kang, Gwangju Institute of Science and Technology, South Korea

${ }^{*}$ Correspondence: Long-Shan Lin linlsh@tio.org.cn Yuan $L$

liyuan1@tio.org.cn

Specialty section: This article was submitted to Marine Fisheries, Aquaculture and Living Resources, a section of the journal Frontiers in Marine Science

Received: 22 June 2021 Accepted: 01 October 2021 Published: 26 October 2021

Citation:

Song $P-Q$, Zhang $H$-S, Zheng $X-Q, L i Y-Y$, Lin L-S and Li Y (2021) Trophic Plasticity of Bombay Duck (Harpadon nehereus) in the South-Central East China Sea Based on Stable Isotope Evidence.

Front. Mar. Sci. 8:728773. doi: 10.3389/fmars.2021.728773

\section{Trophic Plasticity of Bombay Duck (Harpadon nehereus) in the South-Central East China Sea Based on Stable Isotope Evidence}

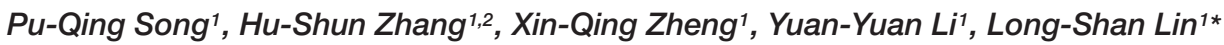 \\ and Yuan Li ${ }^{1 *}$ \\ ${ }^{1}$ Third Institute of Oceanography, Ministry of Natural Resources, Xiamen, China, ${ }^{2}$ Shanghai Ocean University, Shanghai, \\ China
}

High trophic plasticity is often invoked to explain the successful expansion of many aquatic species. Bombay duck (BD) outcompete other traditionally commercial fishes in the East China Sea (ECS) in recent years, displaying a continuous and sharp increase of catches, however, little is known whether the competition advantage of BD was related to its trophic plasticity. Using stable isotope analysis (SIA), we investigated the trophic ecology of BD in the south-central ECS in two periods. Significant differences in $\delta^{13} \mathrm{C}$ and $\delta^{15} \mathrm{~N}$ values were found between sampling months and among body sizes. Modal (95\% credibility limits) estimation showed that BD's trophic position (TP) gradually increased from 3.56 (3.31-3.82) in G1 (120-150 mm for body size) to 4.09 (3.69-4.50) in G5 (241-270 mm) in November, and from $3.37(2.92-3.88)$ in G2 (151-180 mm) to 3.66 (3.07-4.23) in G4 (211-240 mm) in April, respectively, suggesting obvious ontogenetic variation of $\delta^{15} \mathrm{~N}$ and TP. More importantly, the TP of BD within the same body size showed wide amplitude, indicating BD possess high trophic plasticity, and can capture prey from low to high trophic levels. Further quantitative analysis based on the MixSIAR model showed that BD mainly fed on zooplankton and fish, but its feeding habit was characterized by the consumption of gradually reduced zooplankton and increased fish associated with increased body size. Interestingly, the fish's contribution to BD showed obvious seasonal variation. It can be explained by varied food availability in ECS. Relatively low fish prey in April forced BD to adjust its diet, adding the ingestion of shrimps and cephalopods corresponding to temporal variations in food availability. The present study provides the evidence that high trophic plasticity exists in the feeding strategy of $\mathrm{BD}$, which is reflected in the ability to adjust the feeding preference according to nutritional needs and food environmental changes; thus, it is competitively advantageous and may partly explain why BD is becoming the predominant species and displays an extensive distribution in the ECS.

Keywords: Bombay duck, stable isotope, East China Sea, trophic level, feeding habits 


\section{INTRODUCTION}

Trophic plasticity is the adaptation of organisms to minimize potential competition for food by (partly) shifting their diets (MacNeil et al., 1997; Lefebvre et al., 2009; Mavraki et al., 2020). It is a form of trophic generalism, implying that a species is capable of feeding on a broad food spectrum, but only exploit a part depending on the competitive environment in which it occurs (Gutt, 2006; Riera, 2009, 2010). Species could adapt their foraging strategy in relation to variation of the availability of their trophic subsidies (Kopp et al., 2015; Timmerman et al., 2021) and the spatial-temporal variation in the food availability may greatly affect the food ingested and diet breadth, making species exhibit a trophic plasticity (Adite et al., 2013). Such plasticity may originate from changes either in direct predation in relation to food environmental variation such as changes in prey abundance or species competition (Zheng et al., 2014), or in indirect predation such as changes in the diet or trophic level of their prey (Timmerman et al., 2021). On the other hand, fish can adjust their diets with size to optimize their energetic return (Scharf et al., 2000). Ontogenetic shifts can be considered a mechanism to avoid, or at least minimize, intraspecific competition by allowing exploitation of different food resources at each developmental stage (García-Rodríguez et al., 2021). Species may shift their diet during ontogenesis and/or there may be changes in resource availability that affect the competitive interactions between them (Winemiller, 1989; Wood et al., 2016). The broader diet spectrum coupled with the trophic plasticity behavior is probably a competitive advantage because it enables species not only to colonize and to adapt to unstable and changing aquatic habitats, but also to invade and to well-establish in various ecosystems (Adite et al., 2013). Evidence suggests that introduced species with generalist diets have the potential for greatest impacts through competition and predation (Cathcart et al., 2019). It is important to well document the diet spectrum variation and the trophic plasticity to explore the species feeding strategies, would give a better insight into the trophic structure dynamic, an important tool and baseline information to conserve, manage and restore fish resources in their habitat (Adite et al., 2013; García-Rodríguez et al., 2021).

Bombay duck (BD, Harpadon nehereus) is a small, inshore, bottom-dwelling predatory fish species, which is widely distributed in the waters of the Indian Ocean and the Northwest Pacific Ocean (Khan, 1989; Ghosh et al., 2009; Lin, 2009; Luo et al., 2012; Firdaus et al., 2017). In China, BD has been regarded as a secondary commercial fish species in the past and is usually caught by coastal nets, so there were no relevant production records available (Lin, 2009). Since the 1980s, the rapid increase in the number of motorized fishing boats has led to an increase in catches year by year, modifies the structure and function of marine ecosystems. Most of the fish species caught in the East China Sea (ECS) have shown characteristics of miniaturization and early maturation, and the resources of some traditional commercial fish species, such as Larimichthys crocea, have declined drastically (Mi, 1997; Lin et al., 2004, 2006; Xu and Liu, 2007; Ma et al., 2019). Under the background of the serious decline in the catch yield in the ECS, BD, as a supplementary fishery resource, is becoming more abundant and gradually becoming one of the main commercial fishes in the ECS (Song et al., 2012; Zhong et al., 2016; Du, 2018).

BD possesses some ecological traits that make it a successful abundant species and ferocious predator in China's coastal waters. The spawning period of BD is from May to September (Luo et al., 2012), which corresponds to summer fishing closure and ensures the safe development of juvenile individuals. At the beginning of the period, $\mathrm{BD}$ moves to inshore waters for spawning and then moves to open sea areas for feeding (Luo et al., 2012). A large mouth split and short intestine allow them to have many choices in the size and species of its prey, ranging from tiny zooplankton to small fish species of the genera Engraulis and Sardinella (Chen et al., 2004; Du, 2018), also suggesting great potential in trophic plasticity for the species. Although limited evidence from stomach content analyses has indicated that BD can switch its diet composition with increased size class, but to date there is little information on BD trophic plasticity (Zhang, 2005; Lin et al., 2010; Pan, 2011; Ghosh, 2014; Du, 2018), some outstanding issues remain. Previous studies have shown that trophic plasticity is to be one of the reasons for the continued high yield of Trichiurus lepturus and the gradual recovery of Larimichthys polyactis in the East China Sea (Yan et al., 2011; Lin and Gao, 2013). BD outcompete other traditionally commercial fishes in the ECS in recent years, displaying a continuous and sharp increase of catches, however, little is known whether the competition advantage of $\mathrm{BD}$ was related to its trophic plasticity. Therefore, the trophic plasticity of BD and how the trophic plasticity is reflected in the process of environmental adaptation and growth need to be further determined.

Stomach content analysis (SCA) is a commonly used method in fish biology. However, SCA only provides information on prey that have been ingested most recently. The contribution of digested prey items is neglected even though their assimilation has contributed to the energy budget of an individual (Wolf et al., 2009). Comparing to SCA, Stable isotopic analysis (SIA) can avoid these deficiencies by indicating the relative contributions of prey items or prey characteristics assimilated over a longer time period, and provide a wider understanding of fish trophic ecology (Zorica et al., 2021). SIA has been widely used in understanding the trophic ecology of marine organisms, such as trophic position, biological migration, and food web dynamics (Zanden et al., 1999; Cherel et al., 2008; Matich et al., 2010; Nilsson et al., 2011; Rolla et al., 2020). Here, we employed an SIA of carbon and nitrogen to investigate variations in the feeding behaviors and trophic ecology of BD in the south-central East China Sea (scECS). We aimed to test whether BD possesses large trophic plasticity and to preliminarily analyze the possible reasons for the resource gradually increasing of $\mathrm{BD}$ in the scECS from the perspective of trophic ecology.

\section{MATERIALS AND METHODS}

\section{Description of Study Area}

The scECS is one of the most productive sea areas for fishery resources in China. The shallow water depth enables sufficient 
light intensity for photosynthesis in continental shelf waters. The front that is formed by the intersection of the Taiwan warm current and the coastal current brings abundant prey and provides favorable hydrological conditions for the fishing grounds in this area (Zheng et al., 2003). These factors make the scECS a suitable ground for breeding, feeding, and overwintering for some commercial fish species (Mi, 1997; Lin et al., 2004). Corresponding to the improvement of fishing equipment and changes in fishing methods, the catch in the ECS experienced three periods: slow growth (1951 to the 1990s), rapid growth (1991 to the 2000s), and a high yield period after the 2000s (Chen, 2004). High-intensity fishing pressure has brought immense economic benefits, but it has also driven a great change in the catch composition in the ECS that is characterized by a decreasing proportion of traditional high-quality catches (such as L. crocea, L. polyactis, and T. lepturus) and an increase in the catch of secondary commercial species (such as Scomber japonicus and H. nehereus) (Zheng et al., 2003; Chen, 2004).

\section{Sampling Collection and Processing for Stable Isotopic Determination}

The study was conducted in November 2018 and April 2019 in the scECS, and a total of 49 sites were chosen within 7 transects, within a water depth range of 30-200 m (Figure 1). The survey vessel was a local bottom trawler with a total power of $258 \mathrm{KW}$ that was assembled with a fishery cod-end net with a width of $27 \mathrm{~m}$ and a mesh size of $20 \mathrm{~mm}$. Trawling at each site lasted approximately $1 \mathrm{~h}$, and the ship's speeds were maintained at approximately 3 knots. All specimens, including $\mathrm{BD}$ and potential prey nekton (i.e., fishes, shrimps, and cephalopods), were collected and frozen $\left(-20^{\circ} \mathrm{C}\right)$. In the laboratory, the biomass (g/hour) of nekton samples was calculated for analysis, and the body size $(\mathrm{mm})$ and weight $(\mathrm{g})$ of $\mathrm{BD}$ were recorded for all individuals. A total of 42 individuals (in 14 stations) of $\mathrm{BD}$ in November was used for SIA and 58 individuals (in 22 stations) in April (Supplementary Table S1). Generally, stable isotope (SI) analysis studies rely on knowledge of isotopic turnover rates (Winter et al., 2019). The metabolic processes in organisms determine the rate at which the isotopic values of a food item are assimilated into body tissue. For fish, muscle tissue was obtained from the dorsal part of fish species. Although there are no studies on the turnover rate of $\mathrm{BD}$, a variable turnover rate was estimated for fish muscles from 39 to 85 days (Busst and Britton, 2018), which is far lower than sampling interval of 5 months in this study. Additionally, our sampling BD in scECS (270 mm, Supplementary Table S1) should be still in a rapid growth stage considering the fact that the asymptotic length of Bombay duck reach $701.4 \mathrm{~mm}$ (Pan, 2011). It suggests that the isotopic turnover rate of $\mathrm{BD}$ might be less than the maximum estimate ( 85 days). BD dorsal muscle in this study was used to analyze the feeding information in two periods (November 2018 vs. April 2019). For shrimps and cephalopods, the soft body parts (flesh) was collected. Additionally, zooplankton was reported to be an important food for BD (Lin et al., 2010; Pan, 2011); therefore, zooplankton were collected using a plankton net (mesh size of $505 \mu \mathrm{m}$ ) using a vertical tow and held in $0.22-\mu \mathrm{m}$ filtered seawater for $24 \mathrm{~h}$ to evacuate the gut contents. Whole body of zooplankton was used for stable isotope analyses. All samples were freeze-dried at $-50^{\circ} \mathrm{C}$ for $48 \mathrm{~h}$, ground to a fine powder and stored dry until subsequent isotope analysis.

Measurements of stable isotope ratios were performed via continuous flow - elemental analysis - isotope ratio mass spectrometry (CF-EA-IRMS) at the Instrument sharing platform of the Third Oceanographic Institute, Ministry of Natural Resources, CHN, using a vario ISOTOPE cube Celemental analyzer (Elementar Analysensysteme GMBH, Hanau, Germany) coupled to an IsoPrime100 isotope ratio mass spectrometer (Isoprime, Cheadle, United Kingdom). The samples were combusted into $\mathrm{CO}_{2}$ and $\mathrm{N}_{2}$ under a high temperature, and the values of ${ }^{13} \mathrm{C} /{ }^{12} \mathrm{C}$ and ${ }^{15} \mathrm{~N} /{ }^{14} \mathrm{~N}$ were compared to international standards (Pee Dee Belemnite and atmospheric $\mathrm{N}_{2}$, respectively). In this study, IAEA-600 was used as working standard material. $\delta^{13} \mathrm{C}$ and $\delta^{15} \mathrm{~N}$ were expressed using the following equation:

$$
\delta^{13} \mathrm{C} \text { or } \delta^{15} \mathrm{~N}=\left(\frac{\mathrm{R}_{\text {sample }}}{\mathrm{R}_{\text {standard }}}-1\right) \times 10^{3}
$$

$\mathrm{R}$ correspondingly represents ${ }^{13} \mathrm{C} /{ }^{12} \mathrm{C}$ and ${ }^{15} \mathrm{~N} /{ }^{14} \mathrm{~N}$, and the standard deviations (SD) of the $\delta^{13} \mathrm{C}$ and $\delta^{15} \mathrm{~N}$ values were generally $<0.1$ and $<0.2 \%$, respectively.

\section{Data Analysis}

Bayesian model using the R package tRophicPosition (QuezadaRomegialli et al., 2018) were applied to estimated trophic position (TP). 95\% credibility interval of BD was calculated. The Bayesian model includes isotopic variation in the baseline indictor, the consumer and in the trophic discrimination in order to provide a robust estimation of consumer TP at the population level. Bivalves with a relatively long lifespan can integrate the isotopic signature at a time scale and from different basal carbon sources, therefore it was commonly used as baseline organisms for estimating trophic level in coastal systems (Zanden and Rasmussen, 2001; Gong et al., 2017; Lin et al., 2021). However, bivalves were found at only a few sites in the scECS. Thus, zooplankton collected at each site were more suitable to be selected as the baseline, as used in the Baltic Sea and the northern Okhotsk Sea (Gorbatenko et al., 2013; Lesutienè et al., 2014). We used the $\delta^{15} \mathrm{~N}$ values of zooplankton with particle sizes greater than $505 \mu \mathrm{m}$ from the study area as the trophic baseline $(\lambda=2)$, and assumed a trophic discrimination factor $\left(\delta^{15} \mathrm{~N}\right)$ of $2.9 \pm 0.3 \%$ (McCutchan et al., 2003). We set the model parameters as follows: baseline $=$ onebaseline, iterations $=20,000$, number of chains (n.chains) $=5$.

Bayesian mixing models were applied to estimate the proportion of prey source contributions to the consumer based on stable isotope analyses using MixSIAR $\mathrm{R}$ package (Stock et al., 2018). MixSIAR uses Markov Chain Monte Carlo method to identify the probability of contributions of food sources to the consumer, taking account of the variances in isotopic composition of food sources, consumers and trophic enrichment factor (TEF). Since there are no available data in literature on TEF for the $\mathrm{BD}$ and the available data for other carnivorous teleost varied widely among species and tissues 


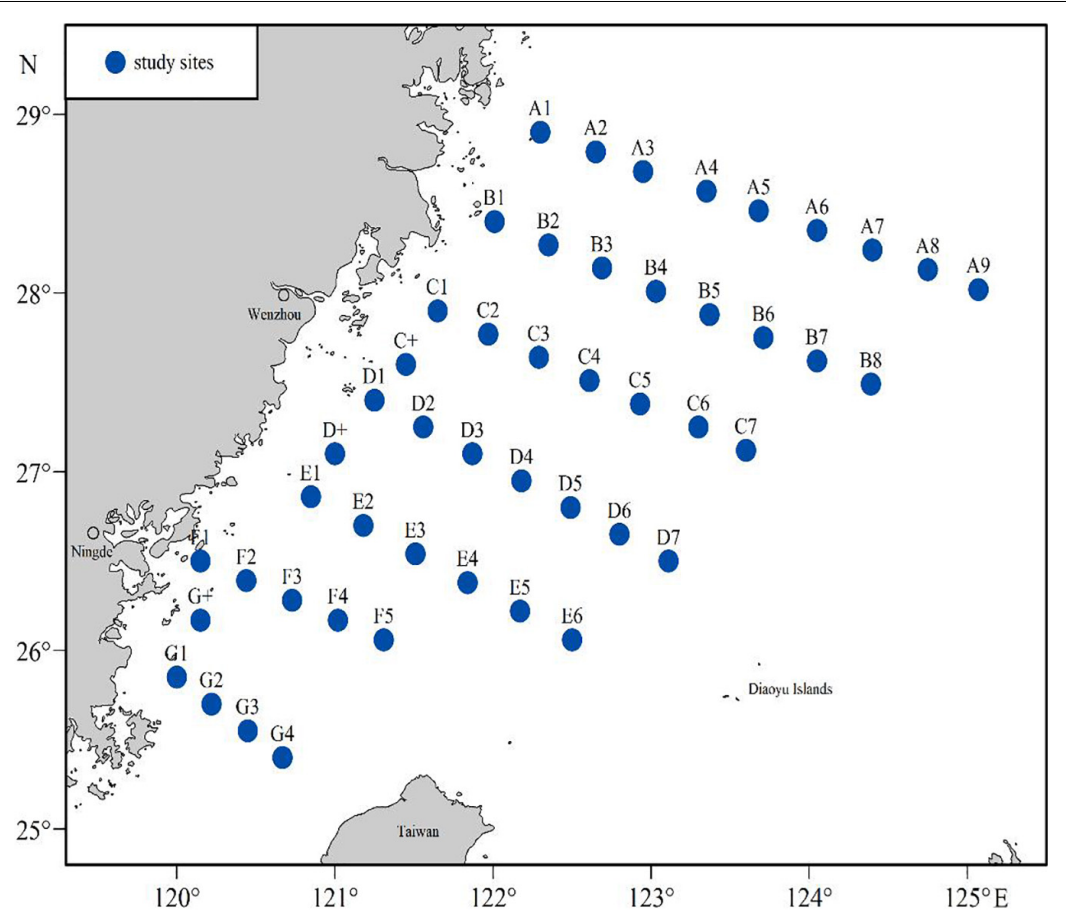

FIGURE 1 | Sites in the south-central East China Sea in November 2018 and April 2019. A total of 49 sites were chosen within 7 transects.

(Matley et al., 2016), we use a TEF following the suggestion on muscle samples by McCutchan et al. (2003) $\left(\Delta^{15} \mathrm{~N}=2.9 \pm 0.32\right.$, $\left.\Delta^{13} \mathrm{C}=1.3 \pm 0.3\right)$. For model inputs, we used "normal" length to achieve model convergence (chain length $=100,000$, burn-in $=50,000$, thin $=50$, chains $=3$ ). Each model was used uninformed priors and assessed model convergence using Gelman-Rubin and Geweke diagnostics.

According to previous stomach content analysis, the potential prey of $\mathrm{BD}$ were classified into seven trophic groups: zooplankton, planktivorous, piscivorous, benthivorous, and omnivorous fishes, shrimps, and cephalopods (Lin et al., 2010; Pan, 2011). The biplots of $\delta^{13} \mathrm{C}$ and $\delta^{15} \mathrm{~N}$ values of BD's prey items showed high overlap in SI ratios between several sources (Figure 2). Phillips et al. (2005) indicated that aggregation should be considered when isotopic signatures of sources were not significantly different and if the combined sources had some functional or ecological significance. Therefore, the seven trophic groups were integrated into four groups: zooplankton, shrimp and cephalopod, planktivorous and piscivorous fishes, benthivorous and omnivorous fishes, before the mixing analysis. And then, to compare the contribution of different taxa, we combined the contribution of two fish trophic groups after estimating their posterior probability distributions to estimate the total contribution of fish by posterior-aggregation (Phillips et al., 2005; Zheng et al., 2015, 2020; Stock et al., 2018). Additionally, considering the positive linear relation between $\delta^{15} \mathrm{~N}$ and body size as well as the significant difference in $\delta^{15} \mathrm{~N}$ among body size groups in this study, BD was divided into five body size groups: 121-150 mm (G1), 151-180 mm (G2), 181-210 mm (G3), 211-240 mm (G4), and 241-270 mm (G5).
We estimated and compared the proportion of prey sources contributions to each group.

One-way analysis of variance (one-way ANOVA) followed by Tukey's HSD post hoc test was applied to examine the differences in stable isotope composition or TP in different sampling periods or size classes. Normality and homogeneity of variance were examined before data analysis, and the K-W test (Kruskal-Wallis test) was carried out if the above data did not conform to the assumptions of ANOVA. Pearson correlation analysis was applied to confirm the correlation between stable isotope values and body size of $\mathrm{BD}$. An independent sample $T$ test was used to examine the differences in the stable isotope composition of the prey among seasons.

\section{RESULTS}

\section{Spatial and Temporal Variation in the Stable Isotope Composition and Biomass of Bombay Duck Prey}

In the scECS, the prey was extremely high in biomass, in which planktivorous fishes were predominantly composed of Bethosema pterotum, and psiviours fishes of $H$. nehereus (Table 1). Additionally, the biomass of the prey displayed interspecies and temporal differences. The biomass was significantly higher in November than in April for total nektonic prey and almost all the fishes, but shrimp showed the opposite trend, especially Solenocera crassicornis. Euprymna berryi and Abralia 


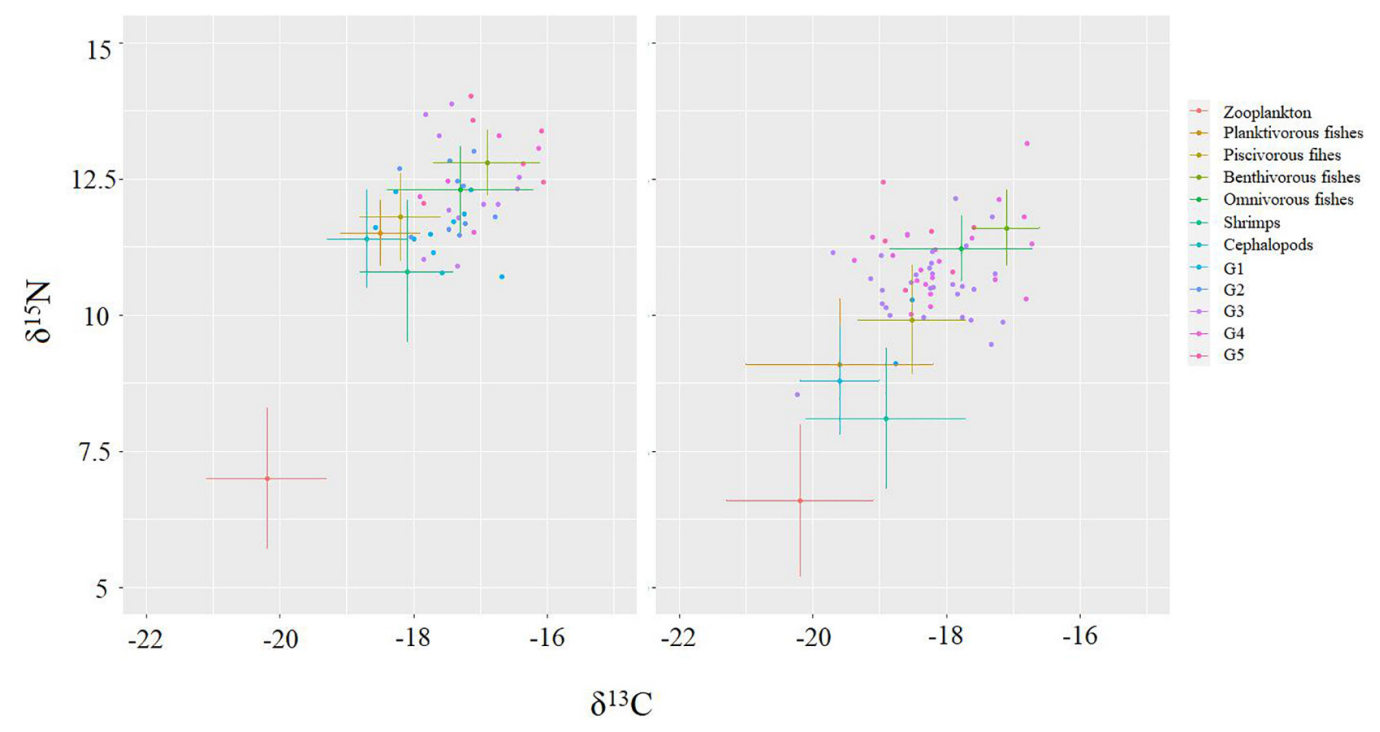

FIGURE 2 | Biplots of $\delta^{13} \mathrm{C}$ and $\delta^{15} \mathrm{~N}$ values of Bombay duck and their prey items. Small color dots represent different size classes of Bombay duck and prey items are shown as mean $( \pm \mathrm{SD})$.

TABLE 1 | Stable isotope signatures (mean \pm SD) and biomass (B) of Bombay duck's prey; $n$ represents the replicates of samples.

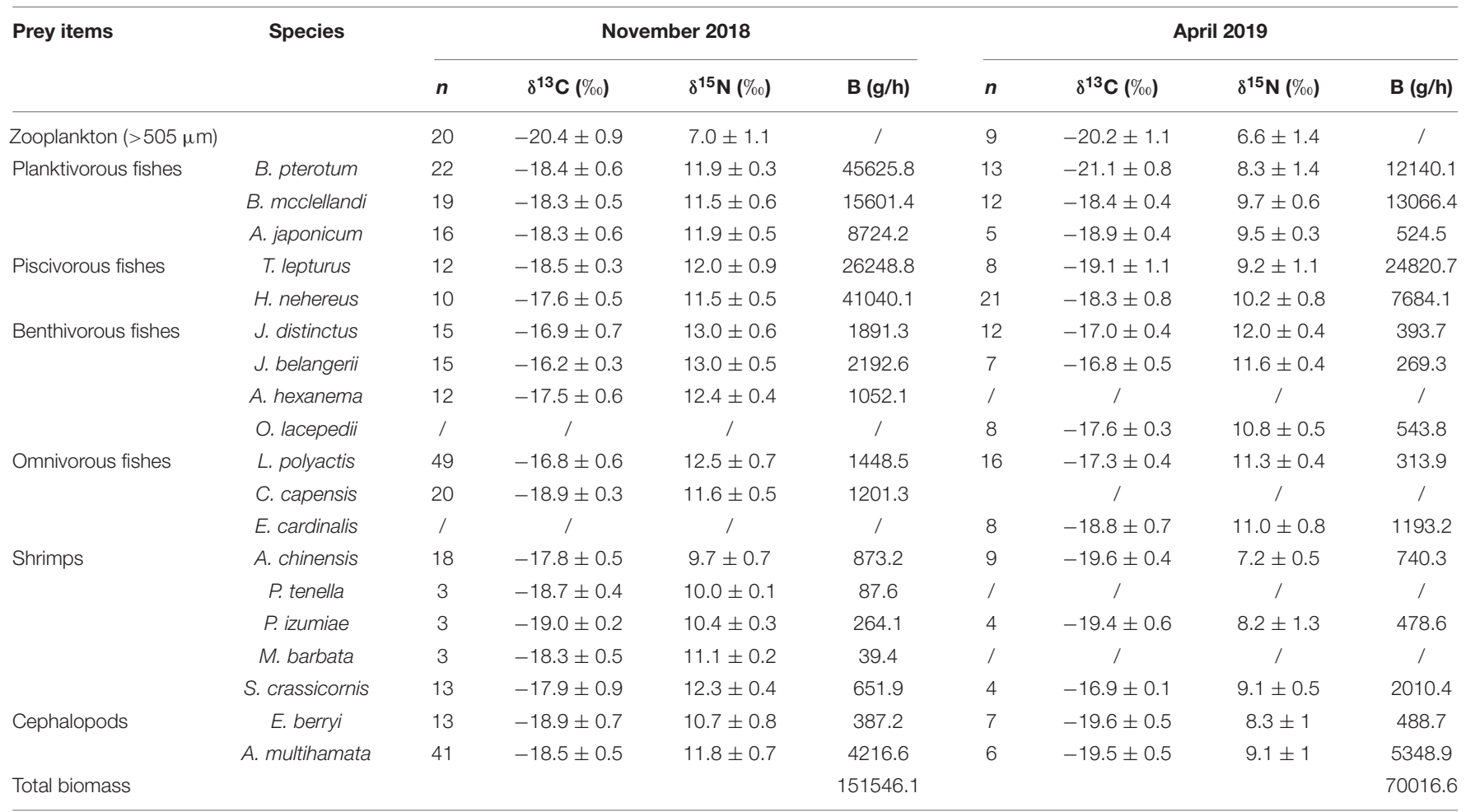

multihamata were two abundant cephalopods, and there was no obviously difference between the two sampling periods.

The $\delta^{13} \mathrm{C}$ mean values of the prey ranged from -21.1 to $-16.2 \%$, while $\delta^{15} \mathrm{~N}$ ranged from 6.6 to $13.0 \%$ (Table 1). Temporal differences in $\delta^{13} \mathrm{C}$ and $\delta^{15} \mathrm{~N}$ values of the prey were detected between sampling periods (Table 2 and Figure 2). There was no significant temporal difference in $\delta^{13} \mathrm{C}$ and $\delta^{15} \mathrm{~N}$ values for zooplankton ( $P=0.663$ and 0.398 , respectively), while a significant difference in $\delta^{15} \mathrm{~N}$ was detected for most of the nektonic prey (Table 2). Although 7 out of 13 species (i.e., B. pterotum, T. lepturus, H. nehereus, Johnius belangerii, Acetes chinensis, E. berryi, and A. multihamata) had more ${ }^{13} \mathrm{C}$-enriched values in November than in April, the $\delta^{13} \mathrm{C}$ difference between the two sampling periods was minor, most of which were less 
TABLE 2 | Temporal variation in stable isotope signatures $\left(\delta^{13} \mathrm{C}\right.$ and $\left.\delta^{15} \mathrm{~N}\right)$ for Bombay duck's prey in the south central East China Sea.

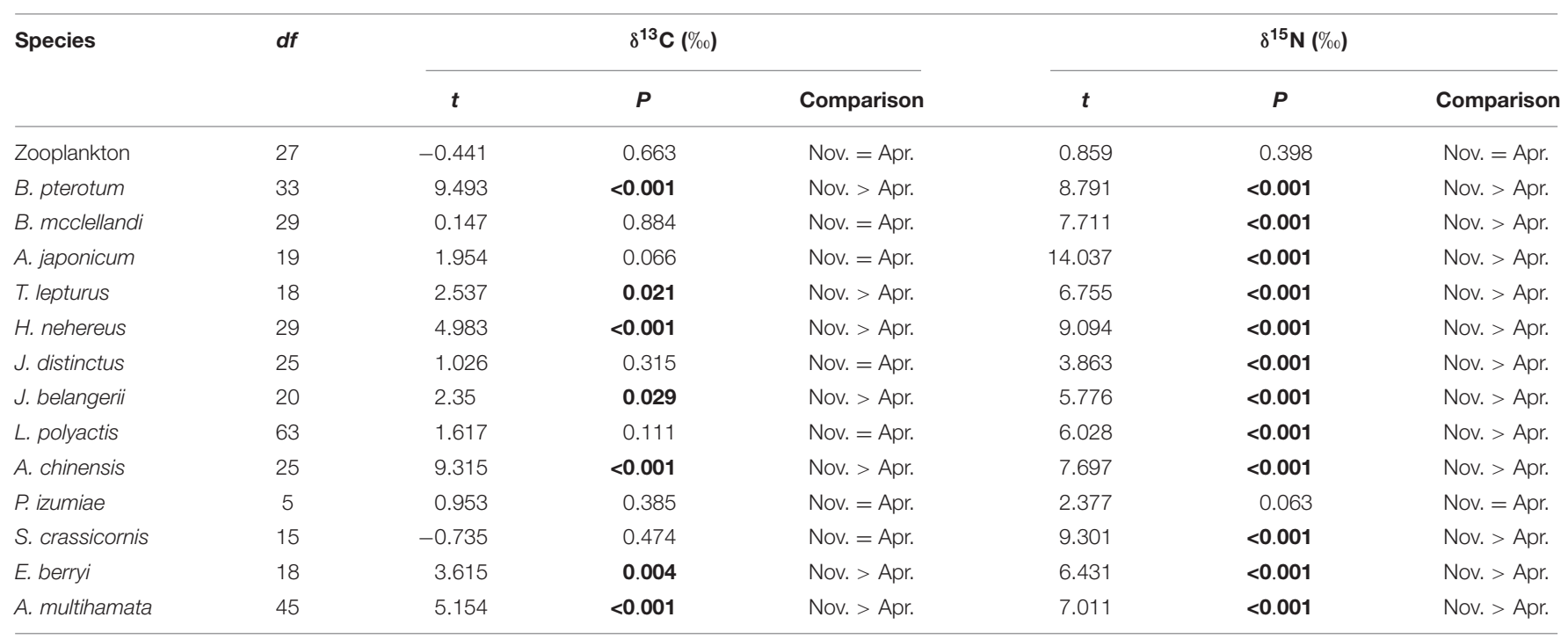

Bold values indicate significant differences $(P<0.05)$.

TABLE 3 | Stable isotopic signatures of Bombay duck in different size groups during both sampling periods.

\begin{tabular}{|c|c|c|c|c|c|c|c|}
\hline \multirow[t]{2}{*}{ Season } & \multirow[t]{2}{*}{ Group } & \multirow[t]{2}{*}{ Size classes $(\mathrm{mm})$} & \multirow[t]{2}{*}{$n$} & \multicolumn{2}{|c|}{$\delta^{13} \mathrm{C}(\% 0)$} & \multicolumn{2}{|c|}{$\delta^{15} \mathrm{~N}(\% 0)$} \\
\hline & & & & Range & Mean \pm SD & Range & Mean \pm SD \\
\hline & G2 & $151-180$ & 10 & $-18.2 \sim-16.8$ & $-17.4 \pm 0.4^{\mathrm{ab}}$ & $11.4 \sim 13.0$ & $12.1 \pm 0.6^{a}$ \\
\hline & G3 & $181-210$ & 11 & $-17.2 \sim-16.4$ & $-17.2 \pm 0.5^{a b}$ & $10.9 \sim 13.9$ & $12.3 \pm 0.9^{a b}$ \\
\hline & G4 & $211-240$ & 5 & $-17.9 \sim-16.1$ & $-17.1 \pm 0.6^{\mathrm{ab}}$ & $11.5 \sim 13.3$ & $12.5 \pm 0.6^{\mathrm{ab}}$ \\
\hline & G2 & $151-180$ & 30 & $-20.2 \sim-17.2$ & $-18.3 \pm 0.7^{c}$ & $8.5 \sim 12.1$ & $10.6 \pm 0.7^{c}$ \\
\hline & G3 & $181-210$ & 20 & $-19.4 \sim-16.7$ & $-18.0 \pm 8.8^{b c}$ & $10 \sim 13.2$ & $11.1 \pm 0.7^{d}$ \\
\hline & G4 & $211-240$ & 6 & $-19.0 \sim-17.6$ & $-18.4 \pm 0.5^{c}$ & $10.5 \sim 12.4$ & $11.4 \pm 0.6^{d}$ \\
\hline
\end{tabular}

Different letters indicate significant differences in each group $(p<0.05)$.

than $1 \%$. However, 12 out of 13 nektonic species (except for Plesionika izumiae) were significantly more ${ }^{15} \mathrm{~N}$-enriched in November than in April, and the $\delta^{15} \mathrm{~N}$ difference ranged from 1 to $3.6 \%$ (Table 2).

\section{Stable Isotope Composition of Bombay Duck}

The isotopic composition of $\mathrm{BD}$ ranged widely, from -18.6 to $-16.0 \%$ for $\delta^{13} \mathrm{C}$ and 10.7 to $14.0 \%$ for $\delta^{15} \mathrm{~N}$ in November and from -20.2 to $-16.7 \%$ for $\delta^{13} \mathrm{C}$ and 8.5 to $13.2 \%$ for $\delta^{15} \mathrm{~N}$ in April (Figure 2; Table 3; Supplementary Table S1). There were significant differences in $\delta^{13} \mathrm{C}$ and $\delta^{15} \mathrm{~N}$ values between November and in April (both $P<0.001$ ). The $\delta^{13} \mathrm{C}$ and $\delta^{15} \mathrm{~N}$ values in April were much lower than those in November (Table 3). The $\delta^{13} \mathrm{C}$ isoscape showed a gradual decline gradient from the northern to southern in November, while in April, it was completely reversed. For $\delta^{15} \mathrm{~N}$, the spatial distribution trend is similar to that of $\delta^{13} \mathrm{C}$, but not so obvious (Figure 3).
Linear regression analysis showed significant correlations between body size and $\delta^{15} \mathrm{~N}$ values of BD in November and April $(r=0.584, P<0.01$ for November and $r=0.460$, $P<0.01$ for April). Similarly, there was a significant correlation between body size and the $\delta^{13} \mathrm{C}$ values of $\mathrm{BD}$ in November ( $r=0.475, P<0.01$ for November) (Figure 4). Marked differences were confirmed in $\delta^{13} \mathrm{C}$ and $\delta^{15} \mathrm{~N}$ values among different size classes, which indicated variations in diet with the growth of BD (Table 3 ).

\section{Trophic Position of Bombay Duck}

Modal (95\% credibility range, CR) estimation showed that BD's trophic position (TP) gradually increased from 3.56 (3.313.82 ) in G1 (120-150 $\mathrm{mm}$ for body size) to 4.09 (3.69-4.50) in G5 (241-270 mm) in November, and from 3.37 (2.92$3.88)$ in G2 (151-180 mm) to $3.66(3.07-4.23)$ in G4 (211$240 \mathrm{~mm}$ ) in April, respectively, suggesting obvious ontogenetic variation of $\delta^{15} \mathrm{~N}$ and TP. Marked variation was detected in the TP of $\mathrm{BD}$ among size classes and between sampling periods 

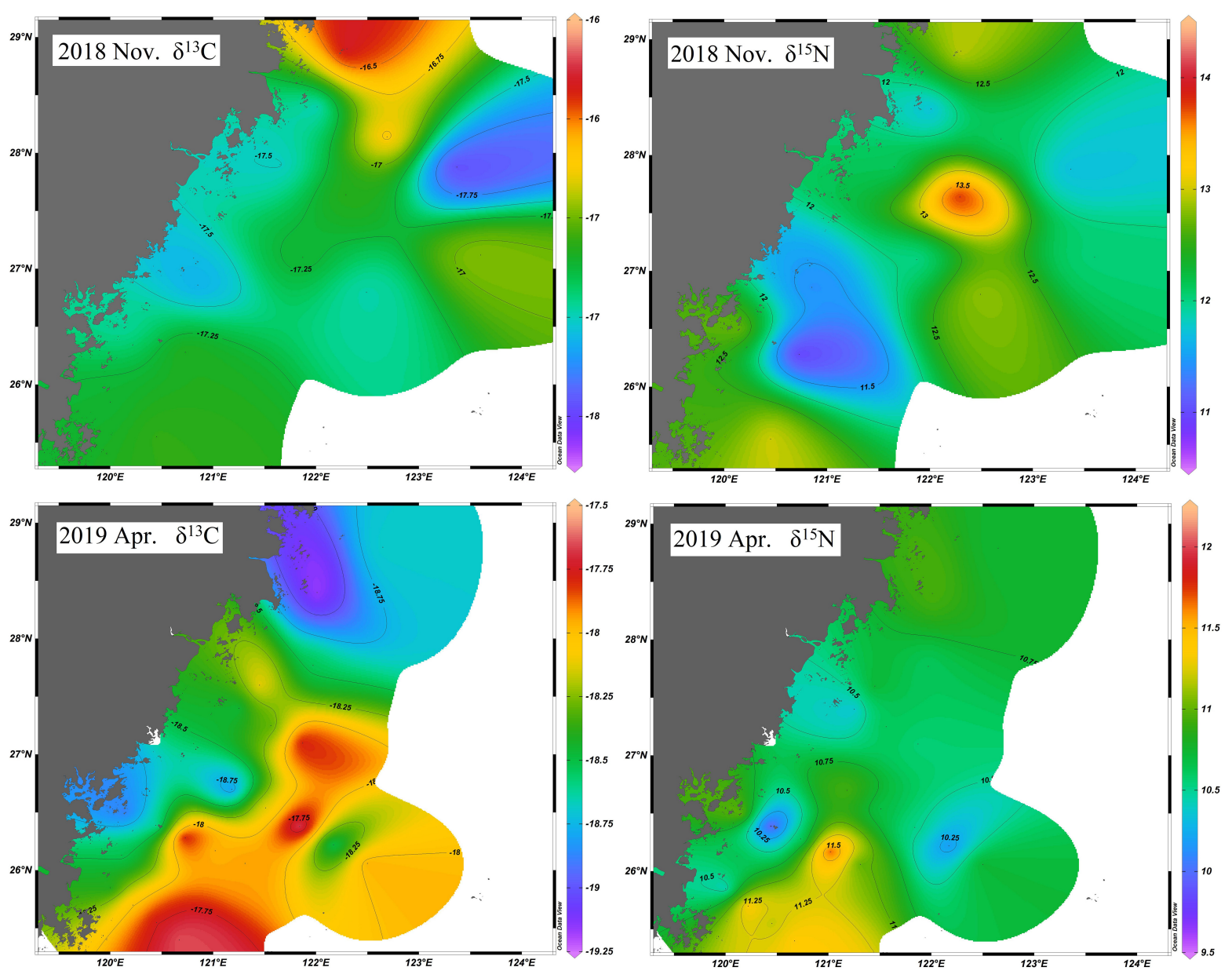

FIGURE $3 \mid \delta^{15} \mathrm{~N}$ and $\delta^{13} \mathrm{C}$ isoscape of Bombay duck in scECS.

(Supplementary Table S2). Modal values of TP generally showed significant higher in November than in April (Figure 5).

\section{Food Items of Bombay Duck and Its Variation}

Mixing models results (Figure 6 and Table 4) indicated that BD mainly fed on zooplankton and fish, but its prey items varied among different size classes. Generally, BD assimilated less zooplankton but more fish with increased body sizes. In November, zooplankton constituted the major diet of $\mathrm{BD}$ in small size classes (median estimate $=57.3 \%, 90 \% \mathrm{CR}=45.5$ $67.9 \%$ in $\mathrm{G} 1$ and median $=46.5 \%, \mathrm{CR}=35.7-56.6 \%$ in G2), and gradually decreased to $30.5 \%(\mathrm{CR}=14.6-43.5 \%)$ in $\mathrm{G} 5$, whereas the fishes' contribution gradually increased from $25.4 \%$ $(\mathrm{CR}=6.6-42 \%)$ to $47.0 \%(\mathrm{CR}=22.4-68.6 \%)$ with size class. The increase trend in zooplankton and the decrease in fish tended to moderate from groups G3 (181-210 mm) to G4 (211$240 \mathrm{~mm}$ ). The dietary contributions of shrimp and cephalopod to $\mathrm{BD}$ among the body size groups were relatively even (16.6-23.3\% with CR among $0-46.5 \%)$. The CR values increased with body size, which indicated that the estimations of the proportional contributions of multiple diet sources were characterized by more and more uncertainty. Similar variations in BD's feeding habit were observed in April, but the increase trend of fish and the decrease trend of zooplankton were still approximately linear from G2 to G4 $\left(R^{2}=0.991\right.$ for fish and $R^{2}=0.959$ for zooplankton, respectively). Comparing the prey contribution of the same size class group in November and April, the zooplankton contribution in April was almost at the same level, while the fish contribution was obviously lower (Table 4). The results of mixing model also supported the variation trend of TP in size class and period.

\section{DISCUSSION}

\section{Isotopic Variations and Trophic Position of Bombay Duck}

Spatiotemporal stable isotopic variations have been extensively studied in different waters, such as lagoons, estuaries, and coastal waters (Goering et al., 1990; Vizzini and Mazzola, 2003; Doi et al., 2005; Zheng et al., 2019). It has been proven that the stable 

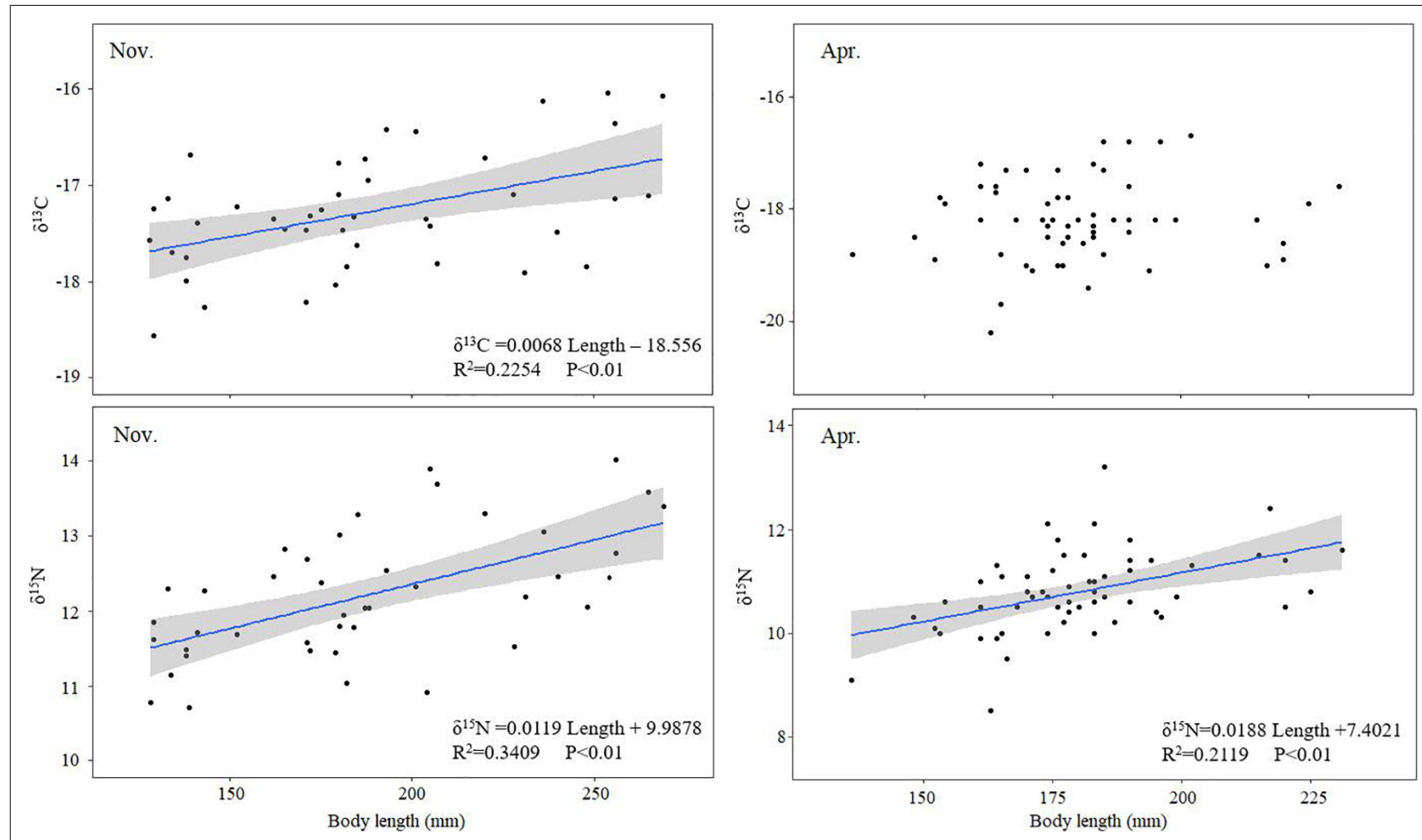

FIGURE 4 | The relationships between the stable isotope signatures $\left(\delta^{13} \mathrm{C}\right.$ and $\delta^{15} \mathrm{~N}$ ) and body length of Bombay duck in November (left) and April (right). The shaded areas represent 95\% confidence intervals and regressions are only shown when significant.

isotope composition varies in consumers living in contrasting environments, such as L. polyactis living in near-shore and offshore waters or the macrozoobenthos and fishes living in lagoons in different seasons due to different compositions of organic matter sources (Ji et al., 2011a; Zheng et al., 2020). In inshore areas easily susceptible to runoff, the mixing of terrestrial and marine-originated carbon might result in variations in $\delta^{13} \mathrm{C}$ inshore and offshore, while $\delta^{15} \mathrm{~N}$ may be affected by enrichment in the ocean or proximity to nitrogen land sources (Sherwood and Rose, 2005). In this study, stable isotopic composition of BD displayed a gradient change from north to south on the whole (Figure 3), though completely opposite trend was observed in two seasons. It to some extent might reflect the temporal change of marine environment in the scECS. The scECS is seasonally affected by two water masses, the Zhejiang and Fujian coastal current (ZFCC) characterized by low temperature and salinity, as well as the Taiwan warm current (TWC) characterized by high temperature and salinity. Under the influence of the northerly winds the ZFCC can be extended to the southern Taiwan Strait in winter and spring, while the TWC controlled most of the scECS in summer and autumn. Different marine environmental characteristics can cause differences in stable isotope ratio of food sources since the origins of carbon sources and other nutrients varied (Uzundumlu and Büyükateş, 2019), and then affect the stable isotope composition of consumers. Our observation shows that the seasonal variation of water mass is quite consistent with the variation of $\delta^{13} \mathrm{C}$. Generally, the $\delta^{13} \mathrm{C}$ value in the area affected by TWC is relatively stable, while the area affected by ZFCC is more complicated due to the joint influence of terrestrial-derived carbon and marine-derived carbon. For $\delta^{15} \mathrm{~N}$, its distribution pattern is similar to $\delta^{13} \mathrm{C}$, but the spatial difference is relatively insignificant. This is consistent with other studies in the ECS, for example, L. polyactis and Pampus argenteus (Ji, 2011). This might be related to the similar composition of prey in the scECS. On the other hand, BD mainly fed on zooplankton and fish, while isotope ratios of pelagic consumers are generally more stable (Sherwood and Rose, 2005).

Our results showed that the $\delta^{13} \mathrm{C}$ and $\delta^{15} \mathrm{~N}$ values varied with body size, suggesting ontogenetic variability in $\mathrm{BD}$, as in other fish species (Currin et al., 2003; Rooker et al., 2006; Ji et al., 2011a; Kimirei et al., 2013; Zhang et al., 2015). Such variation in size could be explained by shifts in dietary preference. For example, it has been proven that the consumption of euphausiids and copepods decreases during the growth of small yellow croaker, whereas the consumption of large prey items, such as decapods and fish, increases (Xue et al., 2010; Ji et al., 2011a). Similar results were also found in a stomach content analysis of $\mathrm{BD}$, which may be responsible for the variations in stable isotope composition (Pan and Cheng, 2011). We also noticed the correlation between the body size and $\delta^{15} \mathrm{~N}$ of $\mathrm{BD}$ was a little weak, although significant. That might be due to the spatial variation of BD's $\delta^{15} \mathrm{~N}$ (Figure 3). The difference would weaken 


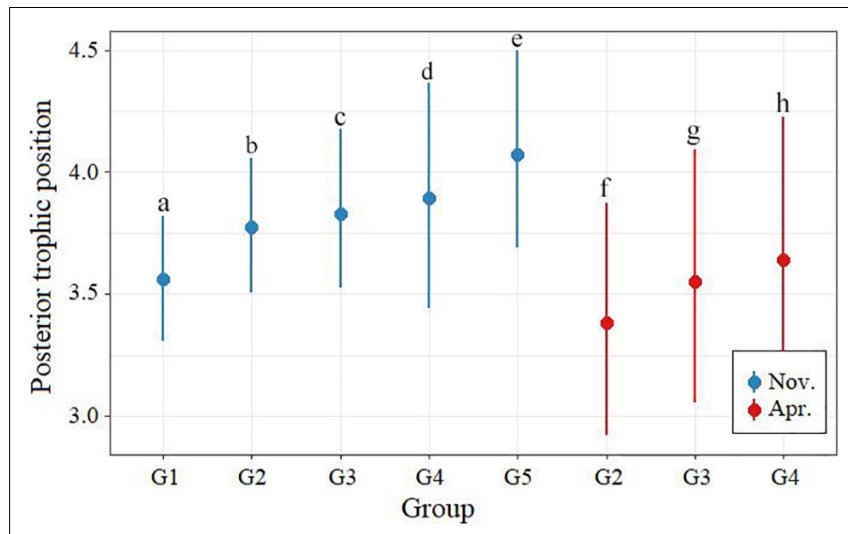

FIGURE 5 | Different body size groups' modal trophic position of Bombay duck in November (blue circles) and April (red circles) with their associated 95\% credibility intervals based on posterior probability distributions. Different letters indicate significant differences in each group.

the regression relationship. Also, a capacity of transtrophic feeding of BD revealed by wide amplitude of trophic position within the same body size (Figure 5), corresponding to food availability, also intensified the weak link. The $\delta^{15} \mathrm{~N}$ values of BD would fluctuate largely in the same body class due to the different diet composition. When high-quality food items was lacking, BD will turn to low-quality food as a supplement. Similar phenomenon also exist in other fish species in the ECS, such as $P$. argenteus $\left(R^{2}=0.24\right)$ and Argyrosomus argentatus $\left(R^{2}=0.175\right)$ (Ji et al., 2011b).

\section{Trophic Position of Bombay Duck}

Due to differences in baseline organisms, TEF and assessment methods, it is difficult to directly compare the TP of BD among studies (Huang et al., 2008; Pan and Cheng, 2011; Yang et al., 2013; Du, 2018; Shi, 2018). However, many studies have indicated that the $\mathrm{TP}$ of fishes in the East China Sea are gradually decreasing, including BD (Pan and Cheng, 2011; Du, 2018; Ma et al., 2019). With the overfishing of fishery resources in this area, the trend of miniaturization and younger age of fish species is obvious, and this may be the internal reason for the decline in the TP of BD (Lin et al., 2006; Du, 2018). However, more likely, it may be that BD's prey has changed dramatically over time and seasonally. It has been proven that the main prey of $\mathrm{BD}$ changed from fish species of the genera Engraulis and Sardinella to some smaller species that mainly prey on zooplankton, such as B. pterotum and B. mcclelland (Pan, 2011; Ghosh, 2014; Du, 2018). In this study, we also find significant seasonal variation in TP (Figure 5) due to the increased contribution of shrimp and cephalopod, while decreased of fish (especially for G2 and G3) in April (Figure 6). Considered there is only half of the biomass for nektonic BD prey caught in April (Table 1), this shift of prey contribution is perhaps caused by the reduction in nektonic prey availability. This temporal fluctuation in food availability would force $\mathrm{BD}$ to feed more on lower-quality resource in its ontogenetic stages in April, leading to a decreasing in TP.
Interestingly, in addition to ontogenetic variation, BD within the same size classes also fluctuates greatly in TP (Figure 5). This indicates a high individual variation of $\mathrm{BD}$ and a wide-ranging prey composition for this species, from low to high trophic levels. This may be partly related to its morphological characteristics. A large mouth split makes $\mathrm{BD}$ more unique than other carnivorous fishes, giving it more choice in the size and items of prey and resulting in a high trophic plasticity of this species.

\section{Feeding Habits of Bombay Duck and Trophic Plasticity}

Zooplankton and fish were the main prey items of $\mathrm{BD}$, which was consistent with previous stomach content analysis (Lin et al., 2010; Pan and Cheng, 2011; Ghosh, 2014). However, the dietary contribution of fish varied between the two methods: median estimate less than 50\% with a broad CR $6.3-68.6 \%$ for the stable isotope method and $80 \%$ for stomach content analysis. In our case, the small size of $\mathrm{BD}$ may be responsible for the difference: the body size of $\mathrm{BD}$ in this study ranges from 120 to $270 \mathrm{~mm}$, and zooplankton contribute more in its ontogenetic stages. However, stomach contents can only reflect the information of instantaneously captured food items in a short time rather than assimilated food items, which can be captured by the stable isotope method. It is difficult to quantitatively analyze zooplankton because it is more easily digested and absorbed compared to fishes, and the results may be biased toward some indigestible food items ( $\mathrm{Li}$ et al., 2005).

The diet of BD varied with body size, and such preference has also been proven in other fish, such as L. polyactis, Trachurus japonicus, and T. lepturus (Guo et al., 2010; Yan et al., 2010; Jiang et al., 2013). These shifts are usually associated with body size, depending on feeding ability and energy requirements, and many studies have also confirmed that changes in feeding organs are one of the main factors that cause diet to change with increasing body size (Wang, 2001; Post, 2003; Pan, 2011). For many juvenile fish, zooplankton are the main prey to support their growth. As body size grows, fish gradually develop feeding organs (such as the mouth split), which makes the juvenile more powerful in hunting. At this stage, predators tend to prey on species of large individuals to ensure sufficient energy sources, which is supported by the "optimal foraging theory" (Gerking, 1994). This shift could expand the dietary resources of the population, meet the nutrition demand at different ontogenetic stages, and alleviate competitive pressure when food resources are limited. The body size thresholds that correspond to dietary changes in BD vary in different studies (Pan, 2011; Du, 2018). In our case, the dietary conversion of $\mathrm{BD}$ did not occur suddenly but shifted continuously with age class. It is characterized by the consumption of gradually reduced zooplankton and increased fish associated with increased body size. Interestingly, the fish's contribution to BD stabilized in November when the body size grew to $211 \sim 240 \mathrm{~mm}$ (G4), it is similar to the result of dietary conversion by stomach content analysis (250 mm; Pan and Cheng, 2011). But fish's contribution will continue to increase in April, this means that BD developed a diet heavily based on nekton in November, 


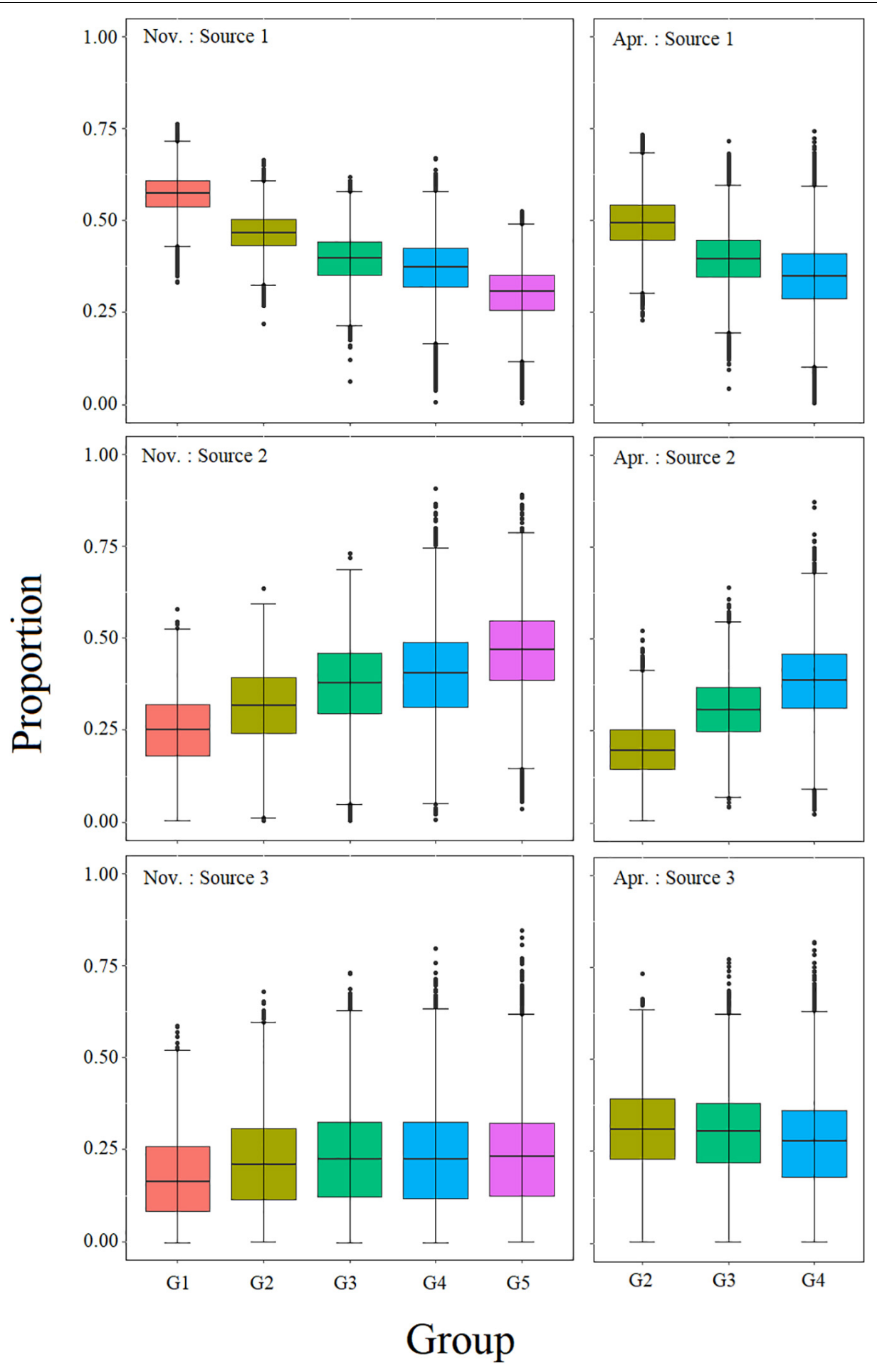

FIGURE 6 | Potential contribution of each resource to the diet of BD in the different body size groups. The different colors represent the different body size groups. The colored boxplots represent the 25 th percentile, the median and the 75 th percentile of the dietary proportions, while the whiskers represent the $1.5 \times$ interquartile ranges (IQR) of the upper and lower quartile. Source 1: zooplankton, Source 2: Fish, Source 3: Shrimp and cephalopod.

but low availability forced a change in April. This might be related to cannibalism habit of $\mathrm{BD}$. Studies show that the prey of $\mathrm{BD}$ is mainly composed of small $\mathrm{BD}$ when its body size is 250-300 $\mathrm{mm}$ (Pan and Cheng, 2011), and BD might have increased feeding of its own species in the deficient of other nektonic prey. This might also explains the shrimp 
TABLE 4 | Estimates proportion of prey species in Bombay duck diet based on Bayesian mixing models using $\delta^{15} \mathrm{~N}$ and $\delta^{13} \mathrm{C}$ values.

\begin{tabular}{|c|c|c|c|c|c|c|c|c|c|c|c|c|c|c|c|c|}
\hline \multirow[t]{2}{*}{ Period } & \multirow[t]{2}{*}{ Prey item } & \multicolumn{3}{|c|}{ G1 } & \multicolumn{3}{|c|}{ G2 } & \multicolumn{3}{|c|}{ G3 } & \multicolumn{3}{|c|}{ G4 } & \multicolumn{3}{|c|}{ G5 } \\
\hline & & Median & $5 \%$ & $95 \%$ & Median & $5 \%$ & $95 \%$ & Median & $5 \%$ & $95 \%$ & Median & $5 \%$ & $95 \%$ & Median & $5 \%$ & $95 \%$ \\
\hline \multirow[t]{3}{*}{ November } & zooplankton & 57.3 & 45.5 & 67.9 & 46.5 & 35.7 & 56.6 & 39.4 & 26.4 & 51.6 & 37.1 & 20.4 & 52.1 & 30.5 & 14.6 & 43.5 \\
\hline & fishes & 25.4 & 6.6 & 42.0 & 32.0 & 11.5 & 50.2 & 38.2 & 13.6 & 58.1 & 40.8 & 15.3 & 63.0 & 47.0 & 22.4 & 68.6 \\
\hline & Shrimp-cephalopod & 16.6 & 0.0 & 38.3 & 21.2 & 0.0 & 43.7 & 22.6 & 0.0 & 46.3 & 22.5 & 0.0 & 46.5 & 23.3 & 0.0 & 46.4 \\
\hline \multirow[t]{3}{*}{ April } & zooplankton & - & - & - & 49.1 & 35.9 & 63.0 & 39.2 & 24.6 & 55.3 & 34.5 & 0.7 & 54.9 & - & - & - \\
\hline & fishes & - & - & - & 19.5 & 6.3 & 36.9 & 30.6 & 14.9 & 48.1 & 38.6 & 16.6 & 59.8 & - & - & - \\
\hline & Shrimp-cephalopod & - & - & - & 30.8 & 8.2 & 52.8 & 30.2 & 5.9 & 51.5 & 27.5 & 0.0 & 49.5 & - & - & - \\
\hline
\end{tabular}

Median, 5 and 95\% values are credible interval outputs from Bayesian isotope mixing models provided.

and cephalopod contribution sudden decrease in G4 in April (Figure 6 and Table 4).

A body of evidence has shown that the spatial and temporal differences in the feeding habits of consumers can be affected by the abundance and type of available prey (Sedberry, 2000; Zheng et al., 2014, 2020; Rolla et al., 2020). When the biomass of the main prey items in the habitat decreases drastically, the small-sized BD with poor predatory ability are under greater food competition pressure, and this pressure can be alleviated by strengthening the predation of zooplankton, shrimp and cephalopod. It also further proves that BD has strong trophic plasticity. High trophic plasticity enables consumers to exploit broad food resources and succeed at interspecific competition. For example, marked differences in the diet and trophic position of top mouth gudgeons (Pseudorasbora parva) have been found in neighboring systems only a few kilometers away, and plasticity in food selection makes them a successful invader in European waters (Rolla et al., 2020).

$\mathrm{BD}$ was not regarded as a fish species of high economic value in the past, but in the context of the severe decline of traditional fishery resources, the increasing catch of $\mathrm{BD}$ re-asserted its commercial value (Lin, 2009; Luo et al., 2012). BD in the ECS is mainly divided into two populations: one is distributed in the northern ECS $\left(30^{\circ} 30^{\prime}-33^{\circ} 30^{\prime} \mathrm{N}, 122^{\circ} 30^{\prime}-126^{\circ} 00^{\prime} \mathrm{E}\right)$, and the other is distributed at $27^{\circ} 00^{\prime}-28^{\circ} 30^{\prime} \mathrm{N}, 121^{\circ} 30^{\prime}-123^{\circ} 00^{\prime} \mathrm{E}$ and is regarded as the southern coastal group featuring less abundance than the northern group (Pan, 2011; Luo et al., 2012). However, a survey of fishery resources in recent years showed that BD in the southern coastal group is becoming the dominant species and has an extensive distribution (Song et al., 2012; Zhong et al., 2016; Du, 2018). Short generation and high fecundity have been considered important factors for population expansion (Rolla et al., 2020). BD possesses a series of ecological traits that make it dominant in the southern ECS, such as growing and maturing rapidly and spawning persistently ( $\operatorname{Pan}, 2011)$. Additionally, the high trophic plasticity of BD may partly explain the success of this species in competition with other fish. Under the multiple influences of environmental changes and fishing pressures, the community structure of the ECS has undergone tremendous changes. It has been proven that some species with higher TLs in the ECS are gradually replaced by some small species that feed on zooplankton (Lin et al., 2006; Dai et al., 2020). In this survey, a variety of small fish species were abundant, such as $B$. pterotum and Bregmaceros macclellandi, and only T. lepturus, as a potential competitor to $\mathrm{BD}$, has a relatively higher biomass (unpublished data). This variation not only alleviates the pressure on BD from competitors but also expands the range of sources of its prey, which guarantees the necessary space and dietary environments for the population extension of BD. The capacity of BD to quickly adjust its food items in its ontogenetic stages and within the same size class enables $\mathrm{BD}$ to be more competitive in their habitats and ensures its nutritional requirements at different ontogenetic stages or environments.

\section{DATA AVAILABILITY STATEMENT}

The raw data supporting the conclusions of this article will be made available by the authors, without undue reservation.

\section{ETHICS STATEMENT}

Animals involved in this research were collected through scientific surveys and were not exposed to any unnecessary pain, injuries or suffering, and no sensitive or endangered species involved in this study. The capture and handling of animal was approved by the Fujian Provincial Department of Ocean and Fisheries (collecting permit LS-100014).

\section{AUTHOR CONTRIBUTIONS}

P-QS, YL, and L-SL contributed to the conception and design of the study. P-QS and H-SZ conducted the field work with sample collection and wrote the first draft of the manuscript. YL and Y-YL analyzed the field survey data. P-QS, X-QZ, and H-SZ analyzed the stable isotopic data. All authors contributed to the manuscript revision and approved the submitted version.

\section{FUNDING}

This work was funded by the National Key Research and Development Program of China (Grant Number: 2018YFC1406302) and the Scientific Research Foundation of Third Institute of Oceanography, MNR (Grant Number: 2019018). 


\section{ACKNOWLEDGMENTS}

We thank Ran Zhang and Cheng Liu for the help in sampling in field, and to the master and crew of Minxiayu 01961 for their cooperation during the surveys.

\section{REFERENCES}

Adite, A., Gbankoto, A., Toko, I. I., and Fiogbe, E. D. (2013). Diet breadth variation and trophic plasticity behavior of the African bonytongue Heterotis niloticus (Cuvier, 1892) in the Sô River-Lake Hlan aquatic system (Benin, West Africa): implications for species conservation and aquaculture development. Nat. Sci. 5 , 1219-1229. doi: 10.4236/ns.2013.512149

Busst, G. M. A., and Britton, J. R. (2018). Tissue-specific turnover rates of the nitrogen stable isotope as functions of time and growth in a cyprinid fish. Hydrobiologia 805, 49-60. doi: 10.1007/s10750-017-3276-2

Cathcart, C. N., Dunker, K. J., Quinn, T. P., Sepulveda, A. J., von Hippel, F. A., Wizik, A., et al. (2019). Trophic plasticity and the invasion of a renowned piscivore: a diet synthesis of northern pike (Esox lucius) from the native and introduced ranges in Alaska, U.S.A. Biol. Invasions. 21, 1-14. doi: 10.1007/ s10530-018-1909-7

Chen, H., Jiao, H., Zhu, J., and Ouyang, Z. (2004). Configurational character and digestive system of Harpodon nehereus. J. Ningbo Univ. 17, 389-392.

Chen, X. (2004). Fisheries Resources and Fisheries. Beijing: China Ocean Press.

Cherel, Y., Ducatez, S., Fontaine, C., Richard, P., and Guinet, C. (2008). Stable isotopes reveal the trophic position and mesopelagic fish diet of female southern elephant seals breeding on the Kerguelen Islands. Mar. Ecol. Prog. 370, 239-247. doi: 10.3354/meps07673

Currin, C. A., Wainright, S. C., Able, K. W., Weinstein, M. P., and Fuller, C. M. (2003). Determination of food web support and trophic position of the mummichog, Fundulus heteroclitus, in New Jersey smooth cordgrass (Spartina alterniflora), common reed (Phragmites australis), and restored salt marshes. Estuaries 26, 495-510. doi: 10.1007/bf02823726

Dai, F., Zhu, L., and Chen, Y. (2020). Variations of fishery resource structure in the yellow sea and East China sea. Prog. Fish. Sci. 41, 1-10.

Doi, H., Matsumasa, M., Toya, T., Satoh, N., Mizota, C., Maki, Y., et al. (2005). Spatial shifts in food sources for macrozoobenthos in an estuarine ecosystem: carbon and nitrogen stable isotope analyses. Estuar. Coastal Shelf Sci. 64, 316-322. doi: 10.1016/j.ecss.2005.02.028

Du, X. (2018). Biological Characteristics and Spatial Distribution Patter of Harpadon Nehereus in Offshore Water of Southern Zhejiang. Shanghai: Shanghai Ocean University.

Firdaus, M., Soemarno, S., Bintoro, G., and Lelono, D. (2017). Growth and age structure of nomei (Harpadon nehereus, Ham. 1822) in Juata Laut Waters of Tarakan Island, North Borneo, Indonesian. Int. J. Sci. Basic Appl. Res. (IJSBAR) 31, 208-218.

García-Rodríguez, E., Vivas, M., Bellido, J. M., Esteban, A., and Torres, M. Á (2021). Ontogenetic shifts and feeding strategies of 7 key species of Gadiformes in the western Mediterranean Sea. Fish. Bull. 119, 50-65. doi: 10.7755/fb.119.1.7

Gerking, S. D. (1994). Feeding Ecology of Fish. San Diego, CA: Academic Press.

Ghosh, S. (2014). Fishery, reproductive biology and diet characteristics of Bombay duck Harpadom nehereus from the Saurashtra coast. Indian J. Mar. Sci. 43, 418-426.

Ghosh, S., Pillai, N. G. K., and Dhokia, H. K. (2009). Fishery and population dynamics of Harpadon nehereus (Ham.) off the Saurashtra coast. Indian J. Fish. 56, 13-19.

Goering, J., Alexander, V., and Haubenstock, N. (1990). Seasonal variability of stable carbon and nitrogen isotope ratios of organisms in a North Pacific Bay. Estuar. Coastal Shelf Sci. 30, 239-260. doi: 10.1016/0272-7714(90) 90050-2

Gong, Y., Chen, L., and Li, Y. K. (2017). Selection of isotopic baselines in marine ecosystems. Chinese J. Appl. Ecol. 28, 2399-2404.

Gorbatenko, K., Melnikov, I., Kiyashko, S., Lazhentsev, A. Y., and Aseeva, N. (2013). The population characteristics and trophic status of herring in the pelagic layer of the northern Okhotsk Sea. Russian J. Mar. Biol. 39, 474-485. doi: $10.1134 / \mathrm{s} 106307401307002 \mathrm{x}$

\section{SUPPLEMENTARY MATERIAL}

The Supplementary Material for this article can be found online at: https://www.frontiersin.org/articles/10.3389/fmars. 2021.728773/full\#supplementary-material

Guo, B., Zhang, B., Dai, F., and Jin, X. (2010). Diet composition and ontogenetic variation in feeding habits of juvenile Setipinna taty in the Haizhou bay. J. Fish. China 34, 921-927. doi: 10.3724/SP.J.1231.2010.06798

Gutt, A. (2006). Coexistence of macro-zoobenthic species on the Antarctic shelf: an attempt to link ecological theory and results. Deep Res. II 53, 1009-1028. doi: 10.1016/j.dsr2.2006.02.012

Huang, L., Zhang, Y., Pa, J., Wu, Y., and Cui, Y. (2008). Food web of fish in Xiamen eastern waters. J. Oceanogr. Taiwan Strait 27, 64-73.

Ji, W. (2011). Ecological Studies on the Food Web Structures and Trophic Relationships of Northern and Central East China Sea Using Stable Carbon and Nitrogen Isotopes. Shanghai: Institute of Oceanology, Chinese Academy of Sciences.

Ji, W., Chen, X., Jiang, Y., and Li, S. (2011a). Trophic ecology of small yellow croaker (Larimichthys polyactis Bleeker): stable carbon and nitrogen isotope evidence. Chinese J. Oceanol. Limnol. 29, 1033-1040. doi: 10.1007/s00343-0110188-2

Ji, W., Chen, X., Jiang, Y., Liu, Y., Hu, F., and Li, S. (2011b). Stable isotope analysis of some representative nektonic organisms in the central and northern part of East China Sea. Mar. Fish. 33, 241-250.

Jiang, R., Jin, H., Zhou, Y., Xue, L., and Guo, A. (2013). Feeding habits of Trachurus japonicus in the East China Sea. Chinese J. Appl. Ecol. 24, 2015-2024.

Khan, M. Z. (1989). Population dynamics of the Bombay duck, Harpodon sehereus (Ham.), off Saurashtra coast. Indian J. Fish. 36, 93-101.

Kimirei, I. A., Nagelkerken, I., Trommelen, M., Blankers, P., Hoytema, N. V., Hoeijmakers, D., et al. (2013). What drives ontogenetic niche shifts of fishes in coral reef ecosystems? Ecosystems 16, 783-796. doi: 10.1007/s10021-0139645-4

Kopp, D., Lefebvre, S., Cachera, M., Villanueva, M. C., and Ernande, B. (2015). Reorganization of a marine trophic network along an inshore-offshore gradient due to stronger pelagic-benthic coupling in coastal areas. Prog. Oceanogr. 130, 157-171. doi: 10.1016/j.pocean.2014.11.001

Lefebvre, S., Leal, J. C. M., Dubois, S., Orvain, F., Blin, J.-L., Bataille, M.-P., et al. (2009). Seasonal dynamics of trophic relationships among co-occurring suspension- feeders in two shellfifish culture dominated ecosystems. Estuar. Coast. Shelf Sci. 82, 415-425. doi: 10.1016/j.ecss.2009.02.002

Lesutienè, J., Bukaveckas, P. A., Gasiūnaitè, Z. R., Pilkaitytè, R., and RazinkovasBaziukas, A. (2014). Tracing the isotopic signal of a cyanobacteria bloom through the food web of a Baltic Sea coastal lagoon. Estuarine Coastal Shelf Sci. 138, 47-56. doi: 10.1016/j.ecss.2013.12.017

Li, Z., Jin, X., Zhuang, Z., Tang, Q., and Su, Y. (2005). Applications of stable isotope techniques in aquatic ecological studies. Acta Ecol. Sin. 25, 3052-3060.

Lin, J., Liu, X., Lai, T., He, B., Du, J., and Zheng, X. (2021). Trophic importance of the seagrass Halophila ovalis in the food web of a Hepu seagrass bed and adjacent waters Beihai, China. Ecol. Indicators 125:107607. doi: 10.1016/ j.ecolind.2021.107607

Lin, L. (2009). Spatial distribution and environmental characteristics of Harpodon nehereus in the East China sea region. J. Shang Ocean Univ. 18, 66-71.

Lin, L., Cheng, J., Ren, Y., and Ling, J. (2004). Analysis of population biology of small yellow croaker Pseudosciaena polyactis in the East China sea region. J. Fish. Sci. China 11, 333-338.

Lin, L., and Gao, T. (2013). Population Biology and Fisheries Management of Small Yellow Croaker. Beijing: China Ocean Press.

Lin, L., Zheng, Y., Liu, Y., and Zhang, H. (2006). The ecological study of small-sized fish in the East China sea I-the species composition and seasonal variation of small-sized fish. Mar. Sci. 30, 58-63.

Lin, X., Zhu, Z., and Li, P. (2010). Feeding habits of Harpadon nehereus in the East China sea region. Mar. Fish. 32, 290-296.

Luo, H., Zhang, H., Li, P., and Zhou, Y. (2012). Analysis of the current situation of fishery biology of Harpadon nehereus in the East China Sea. J. Zhejiang Ocean Univ. 31, 202-205. 
Ma, S., Liu, Y., Li, J., Fu, C., Ye, Z., Sun, P., et al. (2019). Climate-induced long-term variations in ecosystem structure and atmosphere-ocean-ecosystem processes in the Yellow Sea and East China sea. Prog. Oceanogr. 175, 183-197. doi: 10.1016/j.pocean.2019.04.008

Matley, J. K., Fisk, A. T., Tobin, A. J., Heupel, M. R., and Simpfendorfer, C. A. (2016). Diet-tissue discrimination factors and turnover of carbon and nitrogen stable isotopes in tissues of an adult predatory coral reef fish, Plectropomus leopardus. Rapid Commun. Mass Spectrom 30, 29-44. doi: 10.1002/rcm.7406

McCutchan, J. H., Lewis, W. M., Kendall, C., and McGrath, C. C. (2003). Variation in trophic shift for stable isotope ratios of carbon, nitrogen, and sulfur. OIKOS 102, 378-390. doi: 10.1034/j.1600-0706.2003.12098.x

MacNeil, C., Dick, J. T. A., and Elwood, R. W. (1997). The trophic ecology of freshwater Gammarus spp. (Crustacea: Amphipoda): problems and perspectives concerning the functional feeding group concept. Biol. Rev. 72, 349-364. doi: 10.1111/j.1469-185x.1997.tb00017.x

Matich, P., Heithaus, M. R., and Layman, C. A. (2010). Size-based variation in intertissue comparisons of stable carbon and nitrogen isotopic composition of bull sharks (Carcharhinus leucas) and tiger sharks (Galeocerdo cuvier). Can. J. Fish. Aquatic Sci. 67, 877-885. doi: 10.1139/f10-037

Mavraki, N., De Mesel, I., Degraer, S., Moens, T., and Vanaverbeke, J. (2020). Resource niches of co-occurring invertebrate species at an offshore wind turbine indicate a substantial degree of trophic plasticity. Front. Mar. Sci. 7:379. doi: 10.3389/fmars.2020.00379

Mi, C. (1997). A study on resources, stock structure and variation of reproductive habit of hairtail Trichiurus haumela in East China sea. J. Fish. Sci. China 4, $7-14$.

Nilsson, E., Solomon, C. T., Wilson, K. A., Willis, T. V., Larget, B., and Zanden, M. J. V. (2011). Effects of an invasive crayfish on trophic relationships in northtemperate lake food webs. Fresh. Biol. 57, 10-23. doi: 10.1111/j.1365-2427.2011. 02688.x

Pan, X. (2011). The Primary Study on Biology of Harpadon Nehereus in the East China Sea. Shanghai: Shanghai Ocean University.

Pan, X., and Cheng, J. (2011). Feeding ecology of Harpadon nehereus in areas adjacent to Changjiang River estuary. J. Fish. Sci. China 18, 1132-1140. doi: 10.3724/sp.j.1118.2011.01132

Phillips, D. L., Newsome, S. D., and Gregg, J. W. (2005). Combining sources in stable isotope mixing models: alternative methods. Oecologia 144, 520-527. doi: 10.1007/s00442-004-1816-8

Post, D. M. (2003). Individual variation in the timing of ontogenetic niche shifts in largemouth bass. Ecology 84, 1298-1310. doi: 10.1890/0012-9658(2003) 084[1298:ivitto]2.0.co;2

Quezada-Romegialli, C., Jackson, A. L., Hayden, B., Kahilainen, K. K., Lopes, C., and Harrod, C. (2018). tRophicPosition, an R package for the Bayesian estimation of trophic position from consumer stable isotope ratios. Methods Ecol. Evol. 9, 1592-1599. doi: 10.1111/2041-210x.13009

Riera, P. (2009). Trophic plasticity in similar habitats: an example which severely limits generalization among ecosystems. Mar. Biodivers. Rec. 2, 1-4. doi: 10. 1017/S1755267209000529

Riera, P. (2010). Trophic plasticity of the gastropod Hydrobia ulvae within an intertidal bay (Roscoff, France): a stable isotope evidence. J. Sea Res. 63, 78-83. doi: 10.1016/j.seares.2009.10.001

Rolla, M., Consuegra, S., and Leaniz, C. G. D. (2020). Trophic plasticity of the highly invasive topmouth gudgeon (Pseudorasbora parva) inferred from stable isotope analysis. Front. Ecol. Evol. 8:212. doi: 10.3389/fevo.2020.00212

Rooker, J. R., Turner, J. P., and Holt, S. A. (2006). Trophic ecology of Sargassumassociated fishes in the Gulf of Mexico determined from stable isotopes and fatty acids. Mar. Ecol. Prog. 313, 249-259. doi: 10.3354/meps313249

Scharf, F. S., Juanes, F., and Rountree, R. A. (2000). Predator size-prey size relationships of marine fish predators: interspecific variation and effects of ontogeny and body size on trophic-niche breadth. Mar. Ecol. Prog. Ser. 208, 229-248. doi: 10.3354/meps208229

Sedberry, G. R. (2000). Tropical estuarine fishes-ecology, exploitation and conservation. Copeia 2001, 880-883. doi: 10.1643/0045-8511(2001)001[0880: ]2.0.co; 2

Sherwood, G., and Rose, G. A. (2005). Stable-isotope analysis of some representative fish and invertebrates of the Newfoundland and Labrador continental shelf food web. Estuar Coast Shelf Sci. 63, 537-549. doi: 10.1016/ j.ecss.2004.12.010
Shi, Y. (2018). Seasonal Variation in Trophic Niche of Common Fish in the Min Estuary Based on Stable Isotope. Xiamen: Jimei University.

Song, P., Zhang, J., Lin, L., Xu, Z., and Zhu, X. (2012). Nekton species composition and biodiversity in Taiwan Strait. Bio. Sci. 20, 32-40. doi: 10.3724/sp.j.1003. 2012.09142

Stock, B. C., Jackson, A. L., Ward, E. J., Parnell, A. C., Phillips, D. L., and Semmens, B. X. (2018). Analyzing mixing systems using a new generation of Bayesian tracer mixing models. Peer J. 6:e5096. doi: 10.7717/peerj.5096

Timmerman, C. A., Giraldo, C., Cresson, P., Ernande, B., Travers-Trolet, M., Rouquette, M., et al. (2021). Plasticity of trophic interactions in fish assemblages results in temporal stability of benthic-pelagic couplings. Mar. Env. Res. 170, 105412-105412. doi: 10.1016/j.marenvres.2021.105412

Uzundumlu, S., and Büyükateş, Y. (2019). Stable isotope compositions of dominant zooplankton species in relation to environmental factors in the Dardanelles. Arch. Biol. Sci. 71, 177-185. doi: 10.2298/abs181003059u

Vizzini, S., and Mazzola, A. (2003). Seasonal variations in the stable carbon and nitrogen isotope ratios $(13 \mathrm{C} / 12 \mathrm{C}$ and $15 \mathrm{~N} / 14 \mathrm{~N})$ of primary producers and consumers in a western Mediterranean coastal lagoon. Mar. Biol. 142, 1009-1018. doi: 10.1007/s00227-003-1027-6

Wang, C. (2001). Study on the Development of Digestive Tract and Food Selection of Pelteobgrus fulvidraco (Riehardson). Wuhan: Huazhong Agricultural University.

Winemiller, K. O. (1989). Ontogenetic diet shifts and resource partitioning among piscivorous fishes in the Venezuelan ilanos. Environ. Biol. Fish. 26, 177-199.

Winter, E. R., Nolan, E. T., Busst, G. M. A., and Britton, J. R. (2019). Estimating stable isotope turnover rates of epidermal mucus and dorsal muscle for an omnivorous fish using a diet-switch experiment. Hydrobiologia 828, 245-258. doi: 10.1007/s10750-018-3816-4

Wolf, N., Carleton, S. A., and Martínez del Rio, C. (2009). Ten years of experimental animal isotopic ecology. Funct. Ecol. 23, 17-26.

Wood, K. A., Hayes, R. B., England, J., and Grey, J. (2016). Invasive crayfish impacts on native fish diet and growth vary with fish life stage. Aquat. Sci. 79, 113-125. doi: 10.1007/s00027-016-0483-2

$\mathrm{Xu}, \mathrm{K}$., and Liu, Z. (2007). The current stock of large yellow croaker Pseudosciaena crocea in the East China sea with respects of its stock decline. J. Dalian Fish. Univ. 22, 392-396.

Xue, Y., Jin, X., Zhang, B., and Liang, Z. (2010). Seasonal, diel and ontogenetic variation in feeding patterns of small yellow croaker in the central Yellow sea. J. Fish Biol. 67, 33-50. doi: 10.1111/j.0022-1112.2005.00677.x

Yan, Y., Chen, J., Hou, G., Lu, H., and Jin, X. (2010). Feeding habits of Trichiurus lepturus in Beibu Gulf of South China Sea. Chinese J. Appl. Ecol. 21, 749-755.

Yan, Y., Hou, G., Chen, J., Lu, H., and Jin, X. (2011). Feeding ecology of hairtail Trichiurus margarites and largehead hairtail Trichiurus lepturus in the Beibu Gulf, the South China sea. Chinese J. Oceanol. Limnol. 29, 174-183. doi: 10. 1007/s00343-011-0004-z

Yang, G., Sun, X., Hou, X., and Chen, C. (2013). Measurement of the trophic level of fish in a coral reef ecosystem using stable isotopes. J. Fish. Sci. China 19, 105-115. doi: 10.3724/sp.j.1118.2012.00105

Zanden, M. J. V., Casselman, J. M., and Rasmussen, J. B. (1999). Stable isotope evidence for the food web consequences of species invasions in lakes. Nature 401, 464-467. doi: 10.1038/46762

Zanden, M. J. V., and Rasmussen, J. B. (2001). Variation in $\delta 15 \mathrm{~N}$ and $\delta 13 \mathrm{C}$ trophic fractionation: implications for aquatic food web studies. Limnol. Oceanogr. 46, 2061-2066. doi: 10.4319/lo.2001.46.8.2061

Zhang, B. (2005). Preliminary Studies on Marine Food Web and Trophodynamics in China Coastal Seas. Qingdao: Ocean University of China.

Zhang, B., Yuan, W., and Wang, J. (2015). Feeding ecology of the dominant fish species in spring in Laoshan Bay. J. Fish. Sci. China 22, 820-827.

Zheng, X., Como, S., Magni, P., and Huang, L. (2019). Spatiotemporal variation in environmental features and elemental/isotopic composition of organic matter sources and primary producers in the Yundang Lagoon (Xiamen, China). Environ. Sci. Pollut. Res. Int. 26, 13126-13137. doi: 10.1007/s11356019-04720-2

Zheng, X., Como, S., Huang, L., and Magni, P. (2020). Temporal changes of a food web structure driven by different primary producers in a subtropical eutrophic lagoon. Mar. Environ. Res. 161:105128. doi: 10.1016/j.marenvres.2020. 105128 
Zheng, X., Huang, L., and Lin, R. (2014). Seasonal shifts in food sources influence feeding habits of three macrozoobenthos species in the Yundang Lagoon: the evidence from stable isotope. Acta Oceanol. Sin. 36, 32-40.

Zheng, X., Huang, L., Lin, R., and Du, J. (2015). Roles of epiphytes associated with macroalgae in benthic food web of a eutrophic coastal lagoon. Cont. Shelf Res. 110, 201-209.

Zheng, Y., Chen, X., Cheng, J., Wang, Y., Shen, X., Chen, W., et al. (2003). The Biological Resources and Environment in Continental Shelf of the East China Sea. Shanghai: Shanghai Science and Technology Press.

Zhong, Y., Yu, C., Zhou, Q., Song, W., Lü, M., Zheng, J., et al. (2016). Species composition and quantitative distribution of fishes in the ningbo-zhoushan port. J. Zhejiang Ocean Univ. 1, 1-7.

Zorica, B., Ezgeta-Baliæ, D., Vidjak, O., Vuletin, V., Šestanoviæ, M., Isajloviæ, I., et al. (2021). Diet composition and isotopic analysis of nine important fisheries resources in the Eastern Adriatic Sea (Mediterranean). Front. Mar. Sci. 8:609432. doi: 10.3389/fmars.2021.609432
Conflict of Interest: The authors declare that the research was conducted in the absence of any commercial or financial relationships that could be construed as a potential conflict of interest.

Publisher's Note: All claims expressed in this article are solely those of the authors and do not necessarily represent those of their affiliated organizations, or those of the publisher, the editors and the reviewers. Any product that may be evaluated in this article, or claim that may be made by its manufacturer, is not guaranteed or endorsed by the publisher.

Copyright (c) 2021 Song, Zhang, Zheng, Li, Lin and Li. This is an open-access article distributed under the terms of the Creative Commons Attribution License (CC BY). The use, distribution or reproduction in other forums is permitted, provided the original author(s) and the copyright owner(s) are credited and that the original publication in this journal is cited, in accordance with accepted academic practice. No use, distribution or reproduction is permitted which does not comply with these terms. 